\title{
Online - Survey in Order to Estimate the Degree of Satisfaction and Loyalty among Computer Technology Users
}

\author{
Irina Anatoleevna Skrinnikova \\ Diana Vladimerovna Shamrai \\ Ramila Ramisovna Cadukova
}

Don State Technical University Email: irina-sk@list.ru

\section{Doi:10.5901/mjss.2015.v6n2s1p489}

\section{Abstract}

\begin{abstract}
The satisfaction of users and customers, and also their loyalty are the main factors of success in any business. Nowadays a great number of companies from different business fields implement a number of actions which form the loyalty of users. However the success of such actions is often rather low. This phenomenon can be partly generated by the fact that the company not always can evaluate the loyalty of users by the best way, in according to that its own efforts in this area of activity and the resulting. Regular survey of satisfaction with service or produces, the loyalty of users towards the company and its produces, monitoring of changes can give the objective performance evaluation of their functioning. The results of marketing survey of loyalty in interconnection with satisfaction of users while using innovative method of online - questioning are described in this very article. Online - questioning is one of the most long-ranged methods of information capturing, because the occurrence of Internet become less problematical for the metropolitan population of Russia. Modern opportunities of realizing marketing survey with the help of that method give the companies more flexible methods of researching target needs, opportunities of sales increasing, working out effective strategies and marketing plans of developing. Today online surveys are advantageous alternative way of getting marketing information in the conditions of significant reduction of the value of survey and the time of questioning, and also the sum of geographical coverage of respondents.
\end{abstract}

Keywords: online-survey, satisfaction, loyalty, promoter net index NPS;

\section{Introduction}

The main purpose of any modern commercial undertaking is profit earning, which can be gained both from realization of goods, and rendering of services. Namely the customer chose which products to buy or whose services to use. Reasoning from this very market postulates we can conclude: the more the producer satisfies interests and foresees customer desires, the more economic benefits he gets. Today a great number of businesses face rather easy problem in what way can their operating benefits be evaluated. One of the sources of information is monthly balance of business which gives certain conception about how effective does the company work? However it's very belated way of getting the information in order to find out quickly how do the customers react on this or that company marketing actions? The leadership of the companies can't take effective measures about the spheres that need improvement without precise estimation of customer's behavior.

The Internet opens up a great number of new opportunities to experts in marketing. Online questionings have been recently used in marketing practice. That is very convenient and fast method of information gathering therefor the quantity of online questionings continues to grow. It is obvious that online questioning is pertinent when the object of survey is online, and is it integral part. The Internet survey is acceptable when the respondent is easily reachable through a worldwide network. In this case, for the business which is connected with computer technologies online questioning is more appropriate than any other method. These facilities while reasonable using can give a great number of valuable and almost free information about customer's preferences and wide audience. Because of feedback from customers business can retrace their reaction on this or that product or service, understand in what direction continue the developing. There are a great number of useful sites that help to hold the online survey of customer's preferences with the help of questioning.

Website www.survio.com was used here to test the satisfaction and loyalty of customer's. Ultimate simplicity and 
minimal resources required for fulfilment, and also reliability and unlimited repetition of cycles of operation were the main development requirements of procedure for valuing the level of satisfaction.

Survio services were officially activated in April 2012, and since that short period of time the users of cite have made themselves sure that this very service is rather convenient for making an online questionnaire, besides the services is for free. By means of several clicks Survio gives a great number of different questionnaire templates, an opportunity to make a questionnaire with professional design and tenor. One can look through response data with the help of different graphs, tabulations, PDF - statements and documents on-line. User's interface is very easy and clear, that is why the users do not need to download or install something essential, besides Survio can be reached by any browser (Online surveys: free and easy: https://my.survio.com/).

In this very service a model of on-line questionnaire was made with a link posted on all affordable sites, forums and groups in the social network. In the survey took part men and women from 16 years old who live in every region of Russia and who did shopping in chain store system "DNS".

As has been mentioned, the aim of the survey is estimation of satisfaction and loyalty of a supermarket chain "DNS" customer's. The company "DNS" (Digital Network System) - is a Russian company, the owner of retail trade system, specialized on sailing computers, digital and household appliances, and also computers manufacturer including laptops and tablets (assembly production). There are 718 shops in 250 cities of Russia at the beginning of 2014. Company headquarters is situated in Vladivostok (DNS Supermarket chain and digital home appliances, http://www.dnsshop.ru/).

Customer's satisfaction, and also their loyalty - is an important success factor in every business. Regular survey of the level of satisfaction and estimation of it, monitoring of changes will give objective assessment of the work of the company.

\section{Research Methodology and Problem Statement}

The problem of keeping the share on the market became more and more relevant nowadays. This is stimulated by increased business competition on the market of computer technologies and Russian market's regular downturn of the scope. According to the end of 2014 year information cutting down of the scopes is observed in every market sector of personal computers, household appliances and electronics (Computers - the Russian market, http://www.tadviser.ru.). The GfK report says that the scope of the market of household appliances and electronics in May- June 2014 has reduced by 4, 5 \% as in 2013 year and reached the point 281, 3 milliard rubles (Electronics market in Russia has returned to the collapse, http://adindex.ru). Another characteristics have also changed: the scope of the market of computers equipment have reduced by $11,8 \%$, office equipment - by $12,2 \%$, audio and video equipment by $3,6 \%$, sailing of cameras reduced by $30,6 \%$. The reason of such kind of downturn is satiation of the market of digital equipment. The changes of sailing scope also are influenced by currency fluctuation and the general economic situation in the country. The reduction in turnover takes place due to wide spreading of cheap models and the reduction of customer's interest towards expensive ones too (Electronics market in Russia has returned to the collapse, http://adindex.ru). And that's not all factors which the companies take account and started thinking about increasing the loyalty of customer's.

One need to understand clearly that satisfaction and loyalty of customers is inseparably connected with prosperity and development of the company in long-term outlook. Differently, the company's success depends on how satisfied and loyal the customers are. New client's attraction is about ten times more expensive than keeping the existing. The high level of client's satisfaction is a strong predicator of their keeping, loyalty and also high demand for goods or services of the company. The rises of client's satisfaction and loyalty should be included in the long-term goals of the business.

For a long time it was considered that customer's loyalty was determined only by their satisfaction, but a numerous surveys have proven that customer's satisfaction not always lead to repeated purchases and increases in sales. The difference is that the satisfaction surveys are headed for measuring of customer's demands as part of an ongoing relationship, while at loyalty survey it is necessary to concentrate on prediction of their behavior and attitude toward the company in future.

Expert in marketing must decide in what way to estimate most closely existing customer's satisfaction and loyalty. There are a number of traditional methods of estimation the level of customer's satisfaction and loyalty.

In this very marketing survey of chain of supermarkets of digital technology "DNS" while analyzing the level of satisfaction and loyalty the following methods were used: score of satisfaction, multiattributive product model, estimation of the number of repeat purchases in digital technology supermarket "DNS", Net Promoter Score (NPS) and assessment rate of "the client's general attitude" to this company.

Obviously, the loyalty is based on the feeling of satisfaction. That is why one of the main questions is how to 
estimate the level of customer's satisfaction with product and service, in what dependence with it is loyalty.

Client's satisfaction - is a term used in marketing. It is the measure of how much do the products and services provided by the company correspond to client's expectations and exceed it. In other words, customer's satisfaction is considered as a degree of coincidence in customer's expectancy. And the marketing expert job is to consider how much does the value of the company's offer correspond to that expectancy. According to the survey of almost 200 senior marketing managers it was found that the estimation of the level of client's satisfaction is very important in control and monitoring of their business Farris, Paul W., Neil T. Bendle, Phillip E. Pfeifer, \& David J. Reibstein (2010).

The score method of estimation was used for rating the level of satisfaction. During that survey the clients were to estimate the level of satisfaction with the chain supermarkets "DNS". The respondents were asked to estimate the level of satisfaction using a 5 - point scale, presented in table 1, Owner O. K. (2013).

Table 1. The scale foe estimating the level of client's satisfaction with chain supermarkets "DNS"

\begin{tabular}{|ccccc|}
\hline 1 & 2 & 3 & 4 & 5 \\
\hline Absolutely not satisfied & Not satisfied & Not satisfied, not disappointed & Partly satisfied & Completely satisfied \\
\hline
\end{tabular}

The results of questioning with the score method are presented in the figure 1.

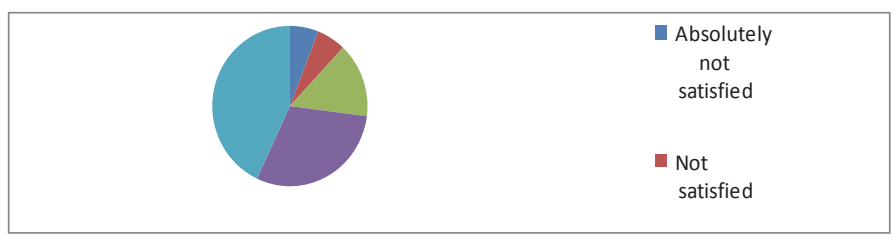

Figure 1. The estimation of client's satisfaction with the chain supermarkets "DNS"

The results of the survey with this method show that:

- Absolutely not satisfied with the activities of the chain supermarkets "DNS" are $6 \%$ of respondents;

- $\quad$ Not satisfied - 6\%;

- $\quad$ Not satisfied, not disappointed $15 \%$ of customers;

- Partly satisfied $30 \%$ of respondents;

- Absolutely satisfied $43 \%$ of respondents.

One the one hand the percentage of absolutely satisfied customers is rather high, on the other hand - the percentage of not satisfied clients who will not do shopping in these chain supermarkets of digital technology and who can respond negatively about the activity of shops is high too. Also it is necessary draw attention on the quantity of respondents who are partly satisfied and who are neutral to the chain supermarkets of digital technology "DNS". There is an equal probability that while making the next purchase they can address to the chain of supermarkets or to competitors, therefore additional stimulating actions are required for their attraction which in their turn will require additional expenditure.

The information about the level of customer's satisfaction is an excellent index of how well or bad the company satisfies the customer's needs. This also can show what should be improved to make the majority of clients completely satisfied.

As far as the customer's satisfaction is formed as a result of complex influence of a great number of factors it is practical to use M. Fishbein's multiattributive model for its estimation, which was adopted for the estimation of the shop.

In this model the satisfaction is determined as a weighted average score of fulfillment or presence of properties of the shop and their importance for the user.

The estimation of properties is carried out in scores. The clients are to estimate the level of satisfaction using a 3point scale, and also to determine significance of every property of the shop.

Besides estimating the attributes of the company and the satisfaction of it in general it is very necessary for expert in marketing to analyses the connection satisfaction/importance.

In the first part of questioning the respondents were to estimate every observable factor while choosing digital technique. 
The results of the survey are presented in the figure 2.

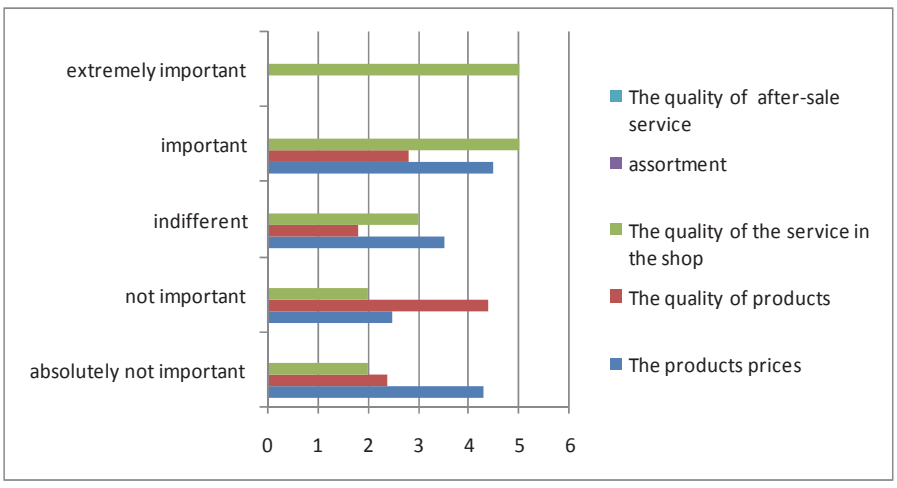

Figure 2. The estimation of factors while choosing the digital technique shop

Further the results of estimation the customer's level of satisfaction with chain supermarkets of digital technique "DNS" on the same indicators are presented.

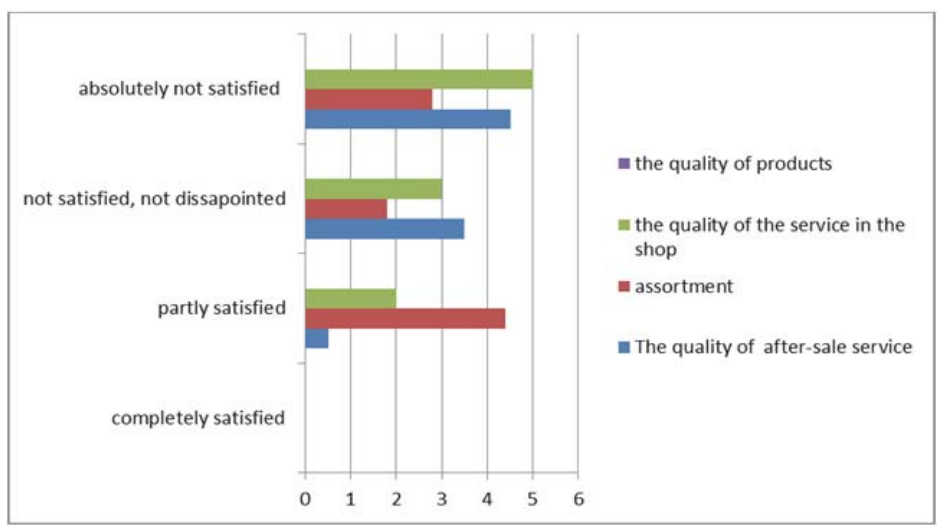

Figure 3. The estimation of satisfaction by digital technique supermarkets "DNS" customers on the basis of multiattributive model

There are summary an analysis of results by "importance/satisfaction" method on the basis of the chain supermarkets of digital technology "DNS" in table 2.

Table 2. The analyses of the results according to "importance/satisfaction" method

\begin{tabular}{|lccc|}
\hline Criteria & Importance & Satisfaction & The location on the map \\
\hline The products prices & 1,28 & 1,2 & 2 \\
The quality of products & 1,64 & 1 & $1 / 2$ \\
The quality of the service in the shop & 0,84 & 0,74 & 3 \\
The assortment & 1,3 & 1,11 & 2 \\
The quality of after-sale service & 1,2 & 0,64 & 1 \\
\hline
\end{tabular}

Using the information presented in the table 2 the profile of satisfaction with digital technique chain supermarkets "DNS" was build (figure 4). 


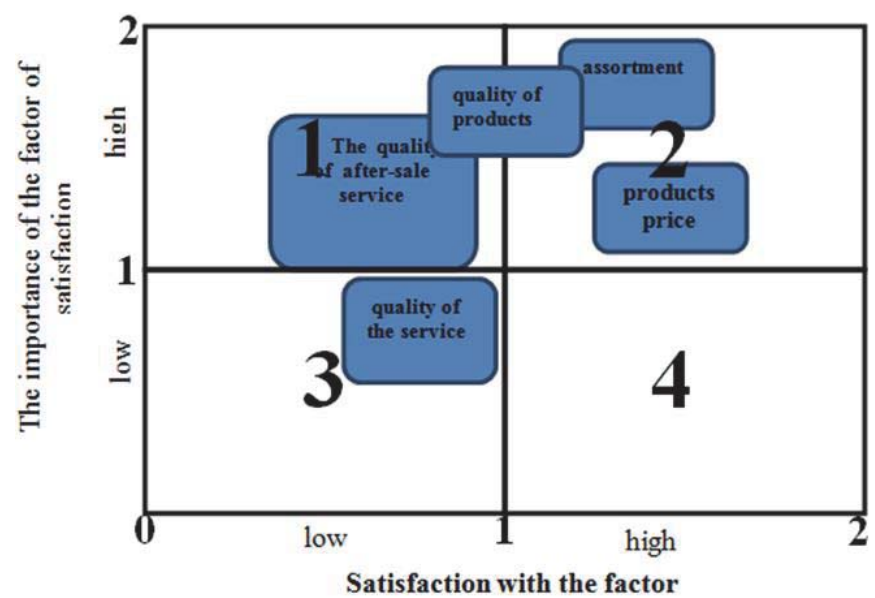

Figure 4. The profile of satisfaction with digital technique chain supermarkets "DNS"

From the carried out analysis the following consequences arise logically:

1. The quality of after-sale service is situated in area 1, which is characterized by low level of satisfaction with the factor besides this factor is very important for the users. A great attention of the leadership and managers of the company should be directed to this area. The problem is to remove strategic disadvantages and to increase client's satisfaction with this attributes.

2. The quality of the products is situated at the intersection of 1 and second area. The high importance of attribute for customer and in this very case the average satisfaction characterizes this factor.

3. The products prices and the assortment of the chain "DNS" refer to the 2 area. A good level of satisfaction with main factors for customer is characteristic of this factor. This is an ideal area because the importance and satisfaction coincide with each other.

4. The quality of the service in the shop is situated in the 3 area - low level of satisfaction with unimportant factors for customer. At first sight we can conclude that this area should be examined as an area of improvement, as long as the low level of satisfaction correspond to low customers rating of attribute. This happens because the high level of service was not as wide spread in Russia as in other countries. However, nowadays change-over to non-price methods of business competition and the high level of service in near future can become an important competitive advantage.

High-quality products and related services made up on the basis of customer's demands, reasonable prices and wide assortment - all this will lead to higher level of customer's satisfaction. The high level of satisfaction will lead to heightening of the level of customer's loyalty, and loyalty is the main determinative of long-term financial success. And though these suggestions seem to be obvious, the results of the survey of company Xerox were unexpected for the leadership: completely satisfied clients purchased iteratively the products six times more likely than just simply satisfied client Christopher, W Hart, \& Michael D. Johnson (1999).

This tendency repeats with long-term experience of other companies who watched the level of customer's satisfaction. Those clients who answered that they were completely satisfied (the highest point), demonstrated high level of loyalty with company (95\%). At the customers who rated the level of their satisfaction as partly satisfied were loyal only to $65 \%$. It is not surprising that in other answers the level of loyalty was rapidly reducing.

On the figure 5 the graph of relationship of customer's satisfaction and loyalty is presented Heskett, J., W. Sasser, \& L. Schlesinger (2010). 


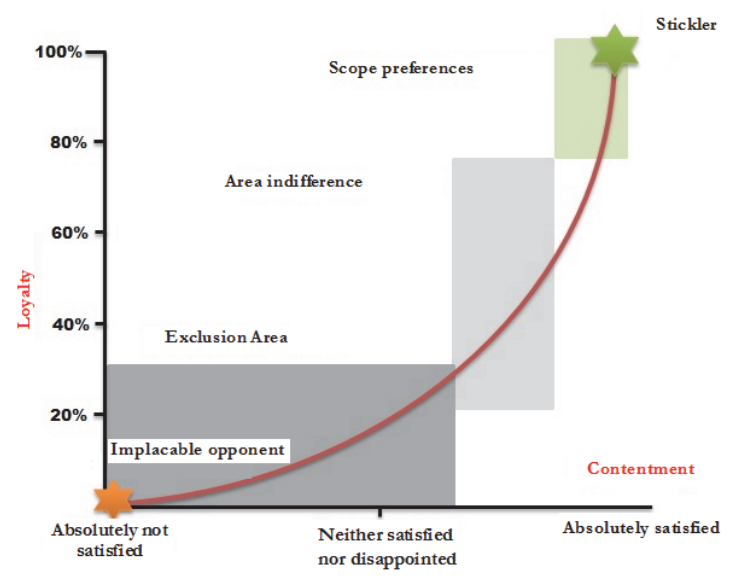

Figure 5. The relationship of customer's satisfaction and loyalty, Heskett, J., W. Sasser, \& L. Schlesinger (2010)

We can conclude from the given information that: the simply satisfied customers have a choice, i.e. when the customer is simply satisfied - this is not enough condition for him to become loyal. So the result is that truly loyal can be called only completely satisfied customers. That small difference between simply satisfied and completely satisfied customers can noticeably change the company characteristics.

The term "loyalty" is regarded as customer's attitude to the product, service or particular company with high level of confidence and insusceptibility to competitor company products. The loyalty of customers - is figuratively-positive attitude of customers towards the company activity, also towards products and services sold, produced or rendered by the organization, the company staff, the image of the organization, trade mark, logo and etc. Namely the existence of customer's loyalty i. e. his good relations to this company or products is the bases of stable sales. Loyal can be called customers who during a long time (comparatively with the terms of the functioning of the goods) remain "loyal" to company and make recurrent purchases.

Let's estimate customer's loyalty on the bases of determining the quality of recurrent purchases. The users of the Internet who used to buy the goods of the digital technique chain supermarkets "DNS" were asked "How many times in the last 12 months have you made purchases in "DNS"?". The results of the questioning are presented in the figure 6.

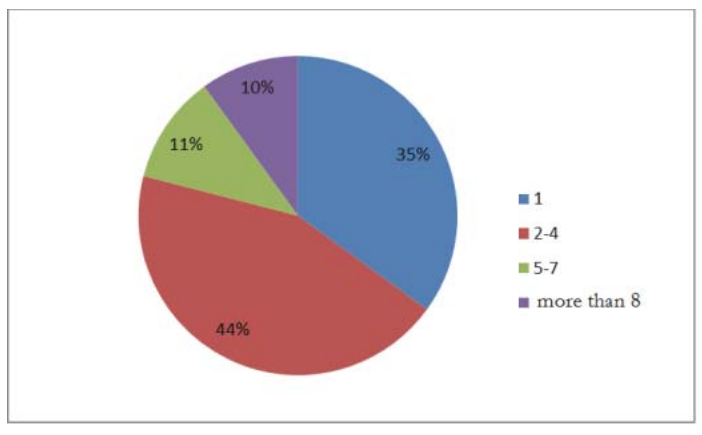

Figure 6. The number of purchases made by one customer in the digital technique chain supermarkets "DNS" during the year

The results of on-line questioning show that among the respondents dominate the customers who have made purchases 2-4 times, their quantity is $44 \%$, after them come customers who have made only 1 purchase $-35 \%$, on the $3^{\text {rd }}$ place are customers who have made purchases 5-7 times during the year - 11\%, the number of customers who apply to "DNS" more than 1 time during the last year is 10\%. From that result we can conclude that the percentage of regular customers of the digital technique chain supermarkets "DNS" is rather high and composed $21 \%$, besides as the Pareto business law 
says in every company nearly $80 \%$ of success in business depend on that $20 \%$ regular customers. Such index amount speaks about the high level of loyalty towards that company.

NPT (NetPromoterScore) is also widespread method of client's loyalty survey. This method is widely used by Russian companies as a separate measurement tool of loyalty and in system with other methods. That is why this method is used in the survey. The internet questioning respondents were to answer:" To what extent are you willing to recommend the digital technique chain supermarkets "DNS" products to your friends, colleagues, acquaintances?". This problem was important while estimating the NPS. Besides, the respondents were to explain their answer in order to estimate the level of loyalty as well as the reason of its absence.

The degree of willingness was estimated on 11-pointed scale, where 10 point means that the user will recommend the company with high probability, 0 - in no event will not recommend, as a result the clients of the company were separated in 3 groups:

- $\quad$ promoters - who put 9 or 10 points;

- $\quad$ satisfied and passive - who put 7 and 8 points;

- critics - who put points from 0 till 6 . This group of users is not satisfied with the company and will not recommend it to others.

NetPromoterScore is the index of loyalty and is calculated as a difference between the percentage ratio of "promoters" and "critics" (figure 7) Owner O. K. (2013).

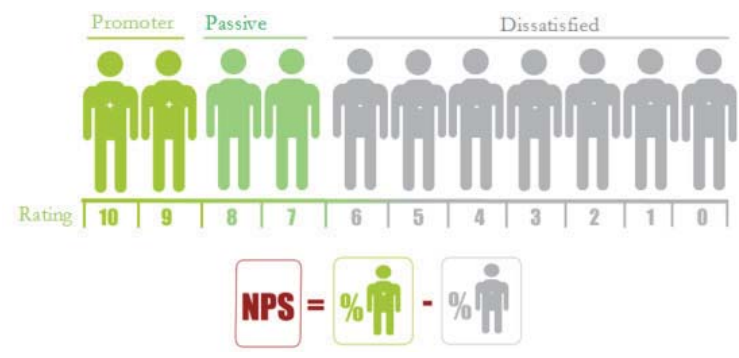

Figure 7. Net Promoter Score index calculation

The results of estimation of the level of loyalty by this method are presented in the figure 8 .

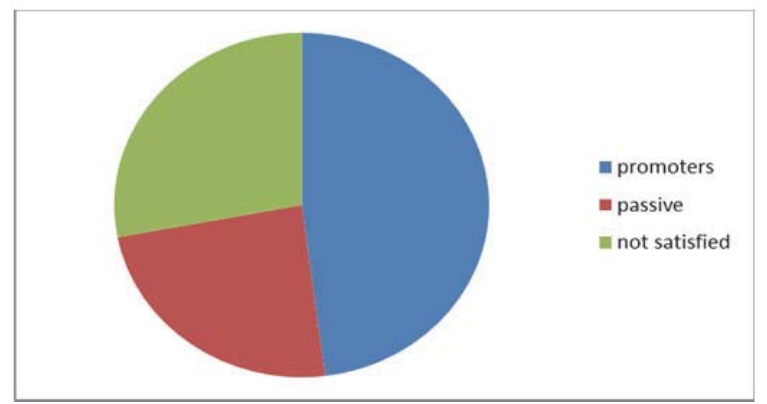

Figure 8. The estimation of customer's satisfaction with the digital technique chain supermarkets "DNS" by the NPS method

Information, presented on the figure 8 let as make the following conclusion - the value of the index NPS is $20 \%$. This is rather high rate which is testified to a high level of the digital technique chain supermarkets "DNS" customer's loyalty. It is considered that the companies who have a high positive NPS index (symbolically +50 and higher) the customer intelligence can increase itself, and the companies can keep themselves from product advertising. Good example is the company Apple which does not need advertising in the global market of digital technologies (Net Promoter Score methodology (NPS), http://radar-research.ru).

Analyzing the answers on the second, open question the following conclusion can be maid: 
- The most popular answer to the question: "Why customer will recommend this company" - excellent ratio of price and quality.

- The most popular answers to the open question of critics i. e. respondents who estimated the "DNS" below 6 points were low quality of after-sales service and low quality of "DNS" products. However, according to results of "importance/satisfaction" survey the quality of after-sales service is not the main criterion while choosing the digital technique shop.

- Also it should be noted that rather big number of respondents answered that the digital technique chain supermarkets "DNS" is the only big supermarket of digital technique in the city, therefore the users do not have the alternative to buy the needed product.

While estimating perceived loyalty the index "general attitude" which shows the general attitude of customers to the company in general was used. The customers were to make a choice of one of the given statements which were presented in the scale Owner O. K. (2013).

Table 3. The scale for measuring the index "general attitude"

\begin{tabular}{|ccccccc|}
\hline 1 & 2 & 3 & 4 & 5 & 6 & 7 \\
\hline This company & I like this company, & I like this & This company is & I treat this company & I don't like this & I don't like this \\
is the best & but there are other, & company, but & acceptable, but & neutrally, it has no & company, although company, it is the \\
among all & equally good & there are better & there are better & distinctive & there are worse & worst out of the all \\
existing & companies & companies & companies & advantages & companies & available \\
\hline
\end{tabular}

The analyses of the results of survey according to this index are presented on the figure 9 .

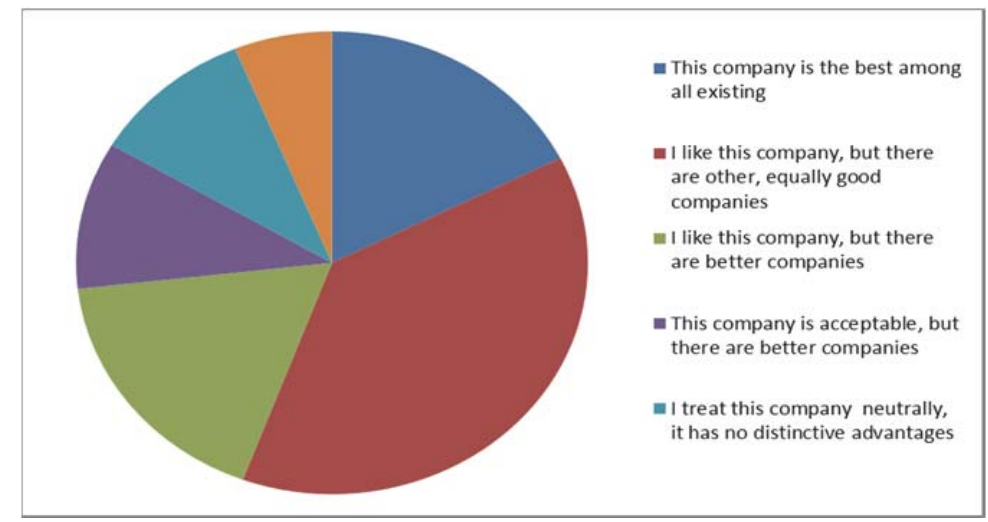

Figure 9. The estimation of index "general attitude" to the digital technique chain supermarkets "DNS"

\section{Concluding Remarks}

The estimation of results of on-line questioning leads to following conclusions:

1. For $17 \%$ of customers this company is the best of all available;

2. $37 \%$ of customers like this company, but they think that there are a number of other companies as good as this one;

3. $17 \%$ of respondents like the company but they think that there are other companies which are better;

4. $10 \%$ of respondents find out the acceptable. And $10 \%$ - relate to the company neutrally, considering that it does not have any distinctive advantages;

5. $6 \%$ of customers do not like this company, although they think there are also companies that are worse than this one.

6. $3 \%$ of clients do not like this company at all, they considered it to be the worst among the available ones.

Summarizing the realized survey of the loyalty of digital technique chain supermarkets "DNS" customers it should be stated that the results of the used methods are rather close: 
- $\quad$ while estimating the number of repeated purchases the percentage of loyal customers is 21;

- while calculating net index of loyalty (NetPromoterScore) - 20\%;

- while estimating the index " general attitude" - $17 \%$ of loyal customers.

Thus the results of realized on-line survey shows that about $20 \%$ of digital technique chain supermarket users are loyal with company. The results speak of the high level of user's loyalty with the digital technique chain supermarkets "DNS".

Clients are ready to continue cooperation with the company even under condition of more advantageous offers from competitors. These results can help the company with the solution of such a strategically important business tasks as increasing of market share by attracting disloyal consumers of its competitors, increasing of sales, retaining of consumers. However, these positive results of survey can't be regarded as unchanged in the long run. Regular monitoring of changes in index of loyalty and satisfaction for further adjustments of the company's strategy for attracting new customers and making the right marketing actions are necessary.

\section{References}

Online surveys for free [Electronic resource]. Access mode: https://my.survio.com/

DNS the chain of supermarkets of digital and home appliances [Electronic resource]. Access mode: http://www.dns-shop.rul

Computers (the Russian market) [Electronic resource]. Access mode: http://www.tadviser.ru.

Electronics market in Russia has returned to the collapse. [Electronic resource]. Access mode: http://adindex.ru.

Farris, Paul W., Neil T. Bendle, Phillip E. Pfeifer, and David J. Reibstein (2010). Marketing Metrics: The Definitive Guide to Measuring Marketing Performance/Upper Saddle River, New Jersey/Pearson Education, Inc.

Owner, O.K. (2013). Management of effectiveness in marketing: a textbook for masters .M.: Publishing company Yurayt, p.343. Series Master.

Christopher, W Hart, and Michael D. Johnson (1999). Marketing Management «Growing the Trust Relationship».

Heskett, J., W. Sasser, and L. Schlesinger (2010) The Service Profit Chain: How Leading Companies Link Profit and Growth to Loyalty, Satisfaction, and Value. Harvard Business School, pp. 320

Net Promoter Score methodology (NPS) [Electronic resource]. Access mode: http://radar-research.ru. 